Pesq. Vet. Bras. 35(9):811-816, setembro 2015 DOI: $10.1590 /$ S0100-736X2015000900007

\title{
Bastonetes Gram-negativos aeróbios e anaeróbios facultativos no fluido ruminal de bovinos de corte alimentados em pastagem lignificada e em novilhos com acidose ruminal $^{1}$
}

\author{
Edvaldo Alves Vieira², Flavia O. Abrão², Izabella Carolina O. Ribeiro ${ }^{2}$, Ana \\ Carolina de A. Nigri² ${ }^{2}$, Kariny F. da Silva², Roberta T. Careli ${ }^{2}$, Luciana C. Geraseev \\ e Eduardo R. Duarte ${ }^{2 *}$
}

\begin{abstract}
Vieira E.A., Abrão F.O., Ribeiro I.CO., Nigri A.C.A., Silva K.F., Careli R.T., Geraseev L.C. \& Duarte E.R. 2015. [Aerobes and anaerobe facultative Gram-negative rod-shaped bacteria in the ruminal fluid of beef cattle fed lignified pasture and steers with ruminal acidosis.] Bastonetes Gram-negativos aeróbios e anaeróbios facultativos no fluido ruminal de bovinos de corte alimentados em pastagem lignificada e em novilhos com acidose ruminal. Pesquisa Veterinária Brasileira 35(9):811-816. Instituto de Ciências Agrárias, Universidade Federal de Minas Gerais, Campus Regional de Montes Claros, Cx. Postal 135, Avenida Universitária 1000, Bairro Universitário, Montes Claros, MG 39404-006, Brazil. E-mail: duartevet@hotmail.com

This study aimed to analyze the population of Gram negative bacteria, rod-shaped aerobic and facultative anaerobes, in ruminal fluid of health Zebu cattle of different categories fed in tropical pasture and steers fed high levels of grain and without bulky. Rumen fluid from 32 cows, 50 steers and 50 calves fed on Brachiaria spp. and 20 steers with ruminal acidosis were collected. After decimal dilutions, the samples were inoculated on petri dishes with agar MacConkey at $39^{\circ} \mathrm{C}$. Biochemical tests were used to identify the most common genera these bacteria. The concentration of these bacteria did not differ in the rumen of cows, calves and calves fed lignified tropical pasture and the most frequently identified genera for these animals were Escherichia, Enterobacter and Klebsiella. However, steers fed without forage and with acidosis showed a higher detection rate and larger population of these bacteria in the rumen $(>6 \mathrm{log} / \mathrm{ml})$ compared to steers fed only pasture. The Escherichia coli species was predominant among theses bacteria isolated from the rumen fluid of steers with acidosis $(\mathrm{p}<0.01)$. In beef zebu cattle raised on pasture lignified, the population of these microorganisms in the rumen is low showing greater diversity of genera. However in confined zebu steers fed without forage and with sub acute ruminal acidosis occur disequilibrium with increased E. coli population.
\end{abstract}

INDEX TERMS: Cattle, Enterobacteriaceae, ruminal microbiota, rumen acidosis, semiarid.

RESUMO.- Objetivou-se analisar a população de bastonetes Gram negativos aeróbios e anaeróbios facultativas no suco ruminal bovinos zebuínos de diferentes categorias, alimentados em pastagem tropical, e de novilhos alimentados com alto teor de grão e sem volumosos. Foram coletados fluido

\footnotetext{
${ }^{1}$ Recebido em 5 de março de 2015.

Aceito para publicação em 22 de setembro de 2015.

${ }^{2}$ Instituto de Ciências Agrárias, Universidade Federal de Minas Gerais (UFMG), Campus Regional de Montes Claros, Cx. Postal 135, Avenida Universitária 1000, Bairro Universitário, Montes Claros, MG 39404-006, Brasil. *Autor para correspondência: duartevet@hotmail.com
}

ruminal de 32 vacas, 50 novilhos e 50 bezerros alimentadas em pastagem de Brachiaria spp. e de 20 novilhos com acidose ruminal. Após diluições decimais, amostras foram inoculadas em placas contendo ágar MacConkey a $39^{\circ} \mathrm{C}$. Para a identificação dos gêneros mais frequentes foram utilizadas provas bioquímicas. A concentração dessas bactérias não diferiu no ambiente ruminal de vacas, novilhos e bezerros de corte alimentados com pastagem tropical lignificada. Os gêneros mais frequentemente identificados para esses animais foram Escherichia, Enterobacter e Klebsiella. Novilhos alimentados sem volumoso e com acidose apresentaram maior taxa de detecção e maior população 
dessas bactérias no ambiente ruminal ( $>6 \mathrm{log} / \mathrm{ml}$ ) quando comparados aos novilhos alimentados somente em pastagem. A espécie Escherichia coli foi predominante entre as bactérias isoladas do fluido ruminal de novilhos alimentados com dieta com alta concentração de grãos e com acidose $(p<0,01)$. Constatou-se que em bovinos de corte, criados em pastagem tropical lignificada, a população desses microrganismos é baixa no ambiente ruminal e com maior diversidade de gêneros bacterianos. Entretanto em novilhos confinados e alimentos sem volumoso, apresentando acidose ruminal subaguda, ocorre desequilíbrio populacional com aumento da população de E. coli.

TERMOS DE INDEXAÇÃO: Bovinocultura, Enterobacteriaceae, microbiota ruminal, acidose ruminal, semiárido.

\section{INTRODUÇÃO}

A dieta dos ruminantes é constituída basicamente de alimentos fibrosos e no decorrer do tempo esses animais, desenvolveram capacidade ingestiva para realizarem simbiose com microrganismos. Dessa forma, obtêm energia para o crescimento, produção e reprodução. A notável capacidade de produção proteica nos ruminantes tem sido atribuída ao sistema de pré-estômagos, que alberga esse complexo ecossistema microbiano (Williams \& Coleman 1991).

Estratégias para prevenir ou reduzir a incidência de bactérias patogênicas na carne de bovinos têm sido pesquisadas para promover maior segurança alimentar e eficiência dos rebanhos (Callaway et al. 2002, Anderson et al. 2005). Essas bactérias estão presentes naturalmente no intestino de humanos e de animais e amplamente distribuídos no ambiente (Stevens 2002). Escherichia coli e Salmonella sp. são agentes relevantes na saúde pública, ocasionam diarreia e mastite aos bovinos, promovendo perdas econômicas na pecuária (Anderson 2005, Duse et al. 2015). Espécies de Enterobacteriaceae podem frequentemente serem encontradas no ecossistema ruminal (Scot et al. 2008, Freitas et. al, 2014).

A utilização do manejo alimentar adequado é de extrema importância para minimizar o desenvolvimento de Enterobacteriaceae, uma vez que animais bem nutridos e sadios possuem menores populações de cepas patogênicas (Rasmussen et al. 2006, Scot et al. 2008). As implicações e as interações desses microrganismos no ambiente ruminal ainda não estão completamente elucidadas principalmente para bovinos alimentados em pastagem tropical lignificada. Pouco se conhece sobre o papel desses microrganismos no rúmen e a interferência na saúde dos animais alimentados com dietas contendo alta concentração de grãos (Khafipour et al. 2011).

Poucos estudos respaldam a interferência da dieta na ocorrência dessas bactérias no ambiente ruminal de animais zebuínos alimentados com e sem volumoso e pouco se conhece sobre as diferenças de populações dessas bactérias em animais de diferentes categorias e criados em pastagens lignificadas. Nesta pesquisa, avaliou-se características físico-químicas e a população de Enterobacteriaceae no fluido ruminal de vacas, novilhos e bezerros de corte criados em pastagem tropical lignificada. Comparou-se também o perfil populacional desses microrganismos entre novilhos alimentados sem volumoso e com acidose ruminal com aqueles alimentados exclusivamente a pasto.

\section{MATERIAL E MÉTODOS}

A amostragem deste estudo foi constituída por 152 bovinos mestiços Nelore, sendo 32 vacas, 50 novilhos e 50 bezerros criados em sistema extensivo e 20 novilhos criados em sistema intensivo que apresentaram acidose ruminal. Os bezerros apresentavam entre seis a oito meses de idade, as vacas possuíam idade superior a quatro anos, e a análise das arcadas dentárias indicou que os novilhos apresentavam 24 a 40 meses de idade. Todos os procedimentos realizados foram submetidos e aprovados pelo comitê de ética em experimentação animal da UFMG pelo protocolo $\mathrm{n}^{\circ}$ 156/05.

0 primeiro estudo foi constituído por 132 bovinos mestiços Nelore criados em sistema extensivo em pastagens tropicais lignificadas com suplementação mineral. As pastagens em que os animais se encontravam eram predominantemente do gênero Brachiaria. As coletas do suco do rúmen ocorreram no período seco da região, quando as pastagens encontravam-se mais lignificadas. A composição nutricional das amostras de pastagens encontra-se descrita no Quadro 1, conforme análise realizada no Laboratório de Nutrição Animal da Universidade Federal de Minas Gerais segundo AOAC (2005).

No segundo estudo foram avaliados 20 novilhos mestiços Nelore confinados durante 71 dias, sendo 11 dias para adaptação e 60 dias para período experimental. Antes da realização do experimento esses animais estavam em pasto de Brachiaria spp. com suplementação mineral. Durante o período da pesquisa receberam somente concentrado peletizado proteico, vitamínico e mineral (15\% da dieta) e grãos de milho inteiros (85\% da dieta), com dois tratos diários. 0 consumo médio da dieta por animal por dia foi de $8,58 \mathrm{~kg}$. 0 produto comercial, na forma de péletes, era constituído por fosfato bicálcio, farelo de algodão, carbonato de cálcio, casca de soja moída, farelo de soja, sulfato de cálcio, uréia pecuária, monensina sódica e premix mineral vitamínico, como reportado pelo fabricante. 0 Quadro 2 apresenta valores nutricionais da dieta completa fornecida aos novilhos do segundo tratamento, conforme análise realizada no Laboratório de Nutrição Animal da Universidade Federal de Minas Gerais segundo AOAC (2005).

Coletas de amostras e análises físico-químicas e microbiológicas

As coletas foram realizadas no período de oito às 11 horas da manhã. Após prévio jejum, os bezerros foram imobilizados em brete de contenção e na parte ventral do abdômen esquerdo dos animais, abaixo da fossa paralombar e cranialmente à articulação do joelho, com aproximadamente $5 \mathrm{~cm} 2$, foram realizadas a tricotomia e a assepsia, com solução de Polivinilpirrolidona-Iodo

Quadro 1. Composição bromatológica de forragens do gênero Brachiaria provenientes de propriedades rurais do Norte de Minas Gerais fornecidas aos animais desse experimento

\begin{tabular}{lcc}
\hline Parâmetros & Montes Claros & Coração de Jesus \\
\hline MS (\% na MN) & 67,75 & 54,65 \\
FDN (\% na MS) & 74,42 & 80,18 \\
FDA (\% na MS) & 39,20 & 45,93 \\
Lignina (\% na MS) & 10,37 & 9,01 \\
PB (\% na MS) & 2,61 & 5,51 \\
EE (\% na MS) & 1,71 & 1,17 \\
Minerais (\% na MS) & 8,68 & 5,70
\end{tabular}

MS = matéria seca, $\mathrm{MN}$ = matéria natural, $\mathrm{FDN}=$ fibra em detergente neutro, $\mathrm{FDA}=$ fibra em detergente ácido, $\mathrm{PB}=$ proteína bruta, $\mathrm{EE}=$ extrato etéreo. 
Quadro 2. Composição bromatológica da dieta sem volumoso fornecida para os novilhos durante 71 dias de confinamento

\begin{tabular}{lc}
\hline Parâmetros & $\begin{array}{c}\text { Dieta completa } \\
\text { (milho grão e concentrado peletizado) }\end{array}$ \\
\hline MS (\% na MN) & 90,23 \\
FDN (\% na MS) & 20,04 \\
FDA (\% na MS) & 6,22 \\
PB (\% na MS) & 17,85 \\
EE (\% na MS) & 3,61 \\
Minerais (\% na MS) & 8,00
\end{tabular}

MS = matéria seca, $\mathrm{MN}$ = matéria natural, FDN = fibra em detergente neutro, $\mathrm{FDA}=$ fibra em detergente ácido, $\mathrm{PB}=$ proteína bruta, EE = extrato etéreo.

(Iodo-PVP) (1\%) (Dirksen 1993). Foram puncionados aproximadamente $15 \mathrm{~mL}$ de fluido ruminal, com o auxílio de cateter humano, acoplado a seringas estéreis.

A punção ruminal nos novilhos e nas vacas, utilizando essa metodologia, mostrou-se ineficiente, uma vez que esses bovinos apresentavam maior espessura da parede abdominal. Por isso, amostras do líquido ruminal desses animais foram obtidas em abatedouro. Após jejum de 12 a 18 horas, esses bovinos foram abatidos por concussão cerebral e sangria.

As análises macroscópicas do líquido ruminal foram realizadas imediatamente após as coletas, em tubos contendo $5 \mathrm{~mL}$ do suco amostrado para avaliação da cor, odor e viscosidade (Dirksen 1993).

Foram realizadas diluições decimais do líquido ruminal em tubos contendo $9 \mathrm{ml}$ de solução salina estéril. Após cada diluição, os tubos foram homogeneizados em vórtex durante um minuto. Alíquotas de $100 \mu \mathrm{l}$ foram inoculadas em placas estéreis contendo o meio ágar MacConkey (Acumedia ${ }^{\circledR}$ Manufactures, Lansing, Michigan - USA).

Para a identificação dos gêneros mais frequentes, foi procedido o reisolamento e o crescimento em placas contendo meio ágar MacConkey em estufa a $39^{\circ} \mathrm{C}$ por 24 horas. Após o crescimento exponencial, cada isolado foi inoculado em tubos contendo meio Rugai e Araújo, modificado por Pessoa e Silva. Nessa classificação foram consideradas a capacidade de produção de indol e sulfetos e gases, a utilização de triptofano, lisina, glicose, sacarose, ureia e a motilidade (McFaddin 2000, Murray et al. 2007).

A diferenças entre as taxas de positividade dos cultivos e a frequencia dos gêneros das bactérias identificadas foram avaliados no teste do quiquadro em tabelas de contigência. Os dados das contagens bacterianas, após analise exploratória, foram avaliados nos testes não paramétricos de Kruskal Wallis para avaliação das categorias e Wilcoxon para as dietas. Utilizou-se o pacote estatístico SAE (2007), considerando a significância de 5\%.

\section{RESULTADOS E DISCUSSÃO}

\section{Características físico-químicas}

Para todos os bovinos alimentados com pastagens tropicais no período da seca, observou-se coloração castanha esverdeada para o líquido ruminal. Animais a pasto normalmente apresentam fluido ruminal com coloração verde oliva ou castanho-esverdeado dependendo das condições da pastagem (Dirksen 1993). 0 odor do fluido foi aromático e a viscosidade foi levemente espessa para todos os bovinos. A redução do azul de metileno foi maior que seis minutos para $62 \%$ dos animais a pasto e menor que um minuto para o restante deles.
Para os animais confinados e alimentados somente com grãos, observou-se fluido ruminal com coloração cinza leitosa. A cor do suco do rúmen é estabelecida de acordo com a alimentação ofertada ao animal. 0 fluido do rúmen de branco a cinza-leitoso sugere acidose ruminal. 0 odor do fluido foi levemente ácido para todas as amostras do segundo experimento. Para todos os novilhos alimentados sem volumoso, o líquido ruminal foi espesso com intensa produção de bolhas de gases, indicando intensa atividade microbiana (Dirksen 1993).

A redução do azul de metileno foi menor que um minuto para $100 \%$ os animais em confinamento. Dietas com níveis elevados de concentrado podem resultar em tempo de redução de apenas um minuto. Por outro lado, o tempo de redução do azul de metileno prolonga-se para até mais de 15 minutos em animais alimentados com dietas pobres em energia e proteína, ou em bovinos com inapetência prolongada (Dirksen 1993). Os dados observados para todas as amostras do segundo tratamento indicam características macroscópicas e físico-químicas de animais com acidose ruminal e com microbiota ruminal intensamente ativa.

As médias de $\mathrm{pH}$ para vacas, novilhos e bezerros alimentados com volumoso foram de 7,3; 7,45 e 7,4 respectivamente. Para os novilhos alimentados somente com concentrado, a média de $\mathrm{pH}$ foi de $5,06(\mathrm{p}<0,01)$, sugerindo acidose ruminal subclínica. Para os novilhos confinados, essa média poderia estar ainda mais reduzida durante o manejo normal desses animais, uma vez que na coleta, estavam em jejum de 12 horas e possivelmente sob efeito tamponante da saliva, durante esse período.

A diminuição no pH do rúmen é ocasionada pela elevação na concentração do ácido lático e dos ácidos graxos voláteis. Com o aumento da osmolaridade do meio, o fluido ruminal torna-se hipertônico em relação ao plasma, provocando maior fluxo de água dos compartimentos intra e extracelulares para o interior do trato digestivo, principalmente no rúmen (Krogh 1999).

\section{Cultivo e quantificação}

Após o cultivo, foi observado o desenvolvimento de bactérias Gram-negativas aeróbias e anaeróbias facultativas em todos os grupos avaliados em porcentagens que variaram entre 56 a $100 \%$ (Quadro 3). Para os animais alimentados com volumoso, a média de unidade formadora de colônia (UFC/ml) e as taxas de positividades não diferiram estatisticamente entre os bovinos de diferentes idades $(p>0,05)$. Diferentemente, em nosso estudo conduzido com bovinos leiteiros da raça Holandesa (Freitas et al. 2014), verificou-se que as bezerras apresentaram maior população dessas bactérias no ambiente ruminal, comparando-se com vacas leiteiras adultas que recebiam a mesma fonte de volumoso (silagem de sorgo).

Comparando a população dessas bactérias para os dois grupos de novilhos, verificou-se que aqueles alimentados sem volumoso e com acidose apresentaram média significativamente maior ( $>6 \mathrm{log} / \mathrm{ml}$ ) que aqueles alimentados somente em pastagem tropical (Quadro3). Bactérias fermentadoras de lactose $(\mathrm{Lac}+$ ) foram detectadas em frequ- 
Quadro 3. Quantificação e positividade em cultivos de bactérias Gram negativo presentes no fluido ruminal de bovinos de corte de diferentes categorias alimentados com pastagem tropical ou de novilhos alimentados sem volumosos e com acidose ruminal

\begin{tabular}{lcccc}
\hline \multicolumn{1}{c}{ Tratamentos } & Quantificação & \multicolumn{3}{c}{ Positividade em cultivos \% } \\
\cline { 3 - 5 } & UFC/ml ${ }^{-1}$ & Totais & Lac- & Lac+ \\
\hline Novilhos com volumoso & $2,5 \times 10^{3} \mathrm{a}$ & $65,6 \mathrm{a}$ & $31,2 \mathrm{a}$ & $65,6 \mathrm{a}$ \\
Vaca com volumoso & $3,7 \times 10^{4} \mathrm{a}$ & $56,0 \mathrm{a}$ & $28,0 \mathrm{a}$ & $42,0 \mathrm{a}$ \\
Bezerro com volumoso & $1,0 \times 10^{4} \mathrm{a}$ & $58,0 \mathrm{a}$ & $34,0 \mathrm{a}$ & $52,0 \mathrm{a}$ \\
Novilhos com volumoso & $2,5 \times 10^{3} \mathrm{~b}$ & $65,6 \mathrm{~b}$ & $31,2 \mathrm{~b}$ & $65,6 \mathrm{~b}$ \\
Novilhos com acidose & $6,4 \times 10^{9} \mathrm{a}$ & $100,0 \mathrm{a}$ & $65,0 \mathrm{a}$ & $100,0 \mathrm{a}$
\end{tabular}

Nota: (Lac-) não fermentadoras de lactose e (Lac+) fermentadoras de lactose. Médias seguidas de letras diferentes na coluna diferem estatisticamente entre si pelo teste de Kruskal Wallis para avaliação das categorias e Wilcoxon para as dietas. A taxas de positividades foram avaliadas com o teste do qui-quadrado. Foram considerados $5 \%$ de significância.

ência significativamente maior para novilhos com acidose (Quadro 3), o que poderia contribuir para o aumento da concentração de ácido láctico e redução do pH.

Essa maior população de bactérias em novilhos alimentados com grãos poderia ser justificada uma vez que esses microrganismos promovem a degradação de carboidratos mais simples (Ostling et al. 2006). Bezerras leiterias alimentadas com cana-de-açúcar e ureia apresentaram elevado número dessas bactérias no fluido ruminal, o que foi relacionado com a maior concentração de carboidrato disponível no volumoso, uma vez que nessa gramínea são detectados altos níveis de sacarose, que é facilmente degradada no rúmen (Freitas et al. 2014).

Krause et al. (2003) avaliaram o efeito da dieta sobre a população Enterobacteriaceae e verificaram grandes concentrações ao longo do trato digestório de bovinos. A dieta foi o principal fator regulador da concentração dessas bactérias, uma vez que bovinos arraçoados com alto teor de grãos apresentaram populações mais numerosas paras esses coliformes.

Em pesquisa realizada com caprinos tratados com infusões intra-ruminais de sacarose verificaram-se clinicamente, sinais de acidose ruminal aguda, tais como: anorexia, apatia, taquicardia, distensão do abdômen, atonia do rúmen, ausência da ruminação, diarreia com fezes escuras, aquosas e fétidas, e perda de peso corporal. Constatou-se ainda evidente decréscimo no $\mathrm{pH}$ ruminal, que atingiu o nível de 4,75 . Consequentemente, a população microbiana foi alterada, com predominância de bactérias lácticas (Miranda Neto et al. 2005). Esses microrganismos utilizam, preferencialmente, carboidratos solúveis, mono e dissacarídeos nos processos fermentativos (Murray et al. 2006).

\section{Distribuição dos gêneros de bactérias}

Os gêneros mais frequentes identificados para os bovinos zebuínos alimentados em pastagem tropical foram Escherichia, Enterobacter e Klebsiella $(\mathrm{p}<0,01)$. Escherichia coli foi mais frequente no fluido ruminal dos novilhos alimentados sem pastagem e com acidose (Quadro 4, $p<0,01$ ). Esse resultado indica que em animais com acidose e alimentados sem volumoso, essa bactéria passa a predominar, indicando desequilíbrio populacional, considerando a distribuição mais homogênea de gêneros verificada para
Quadro 4. Distribuição dos Gêneros de Bastonetes Gramnegativos aeróbios e anaeróbios facultativos no fluido ruminal de bovinos mantidos em pastagem tropical ou com dieta sem volumoso

\begin{tabular}{|c|c|c|c|c|c|c|c|c|c|}
\hline \multirow[t]{3}{*}{ Gêneros } & \multirow{3}{*}{$\begin{array}{c}\text { Total } \\
\mathrm{N}\end{array}$} & \multirow{2}{*}{\multicolumn{2}{|c|}{$\begin{array}{c}\text { Com acidose } \\
\text { Novilhos } \\
\end{array}$}} & \multicolumn{6}{|c|}{ Bovinos mantidos em pastagem } \\
\hline & & & & \multicolumn{2}{|c|}{ Novilhos } & \multicolumn{2}{|c|}{ Vacas } & \multicolumn{2}{|c|}{ Bezerros } \\
\hline & & $\mathrm{n}$ & $\%$ & $\mathrm{n}$ & $\%$ & $\mathrm{n}$ & $\%$ & $\mathrm{n}$ & $\%$ \\
\hline Escherichia & 60 & $43 *$ & 71,6 & 6 & 10 & 7 & 11,4 & 4 & 7 \\
\hline Alcaligenes & 3 & - & 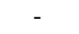 & 2 & 5,5 & 1 & - & - & - \\
\hline Edwardsiella & 5 & 1 & 1,6 & 4 & 11,6 & - & - & - & - \\
\hline Enterobacter & 26 & 8 & 30,7 & 7 & 26,9 & 6 & 23,3 & 5 & 19,1 \\
\hline Klebsiella & 28 & 6 & 21,4 & 7 & 25,7 & 5 & 17,9 & 10 & 35,0 \\
\hline Proteus & 9 & 2 & 3,7 & 5 & 13,5 & - & - & 2 & - \\
\hline Pseudomonas & 12 & 3 & 25,0 & 5 & 42,0 & 4 & 33,0 & - & - \\
\hline Total & 143 & 63 & & 36 & & 23 & & 21 & \\
\hline
\end{tabular}

* Valores significativos maiores quando comparados entre os tratamentos e entre os gêneros pelo teste de Qui-quadrado $(\mathrm{p}<0,01)$.

os outros grupos de bovinos alimentados naturalmente em pastagens. Esse resultado corrobora com outras pesquisas que relataram que as populações totais de E. coli foram abundantes no rúmen de bovinos alimentados com maiores teores de grãos do que aqueles alimentados à pasto (Scot et al. 2008; Khafipour et al. 2011).

Os resultados deste estudo corroboram com aqueles descritos por Diez-Gonzalez et al. (1998) que relataram que vacas leiteiras alimentadas com grãos apresentaram população elevada de E. coli ácido-resistente e que para aquelas alimentados com feno ou pastagem fresca, a população dessa bactéria foi reduzida significativamente.

Em outra pesquisa, a população de E. coli no fluido ruminal de bovinos alimentados com silagem de milho foi significativamente maior que em bovinos alimentados com feno de azevém e pastagem fresca (Jacobson et al. 2002). Segundo os autores esse resultado poderia ser justificado uma vez que a silagem de milho continha maiores concentrações de carboidratos simples de fácil degradação.

Nesta presente pesquisa, não foram verificadas diferenças significativas na distribuição dos gêneros isolados do fluido ruminal de novilhos, vacas e bezerros alimentados em pastagem. Entretanto, em nosso estudo anterior, verificou-se que vacas leiteiras adultas, alimentadas com silagem de sorgo possuíam maior ocorrência Klebsiella spp. do que bezerras alimentadas com a mesma dieta (Freitas et al. 2014).

As interações e implicações de Enterobacteriaceae no rúmen ainda não são totalmente elucidadas. Ruiz-Lacaz et al. (1992) relatam que algumas bactérias dessa família possuem efeito benéfico na diminuição de oxigênio ruminal. Aung et al. (2006) reporta que Klebsiella spp. possui potencial para degradação de mimosina, composto tóxico presente na leguminosa forrageira Leucaena leucocephala, o que sugere que uma vez fornecida aos animais, a dieta contendo silagem de sorgo pode ser considerada fator favorecedor para essa bactéria, e poderia reduzir os riscos de intoxicação para os animais alimentados com essa leguminosa. Lin et al. (2010) apontam que o potencial biotecnológico dessas bactérias é promissor, uma vez que cepas de Klebsiella oxytoca isoladas a partir de fezes de ovelha foram utilizadas na bioconversão direta do capim elefante (Penni- 
setum alopecoider) para etanol. A espécie Enterobacter ludwigii isolada do rúmen de caprinos foi capaz de produzir enzimas para degradação de taninos, o que poderia reduzir esse fator antinutricional no rúmen desses animais (Singh et al. 2012).

Nesta presente pesquisa, novilhos alimentados sem volumoso e com alta concentração de grãos apresentaram acidose ruminal subaguda e a população de $E$. coli foi significativamente maior (Quadro 4), sugerindo um ambiente ruminal mais favorável para essa bactéria que é considerada um dos principais agentes de zoonoses do trato digestório de ruminantes (Russell et al. 2000). Pesquisas indicam que o manejo alimentar adequado, com maior proporção de volumosos, é fator determinante no controle de cepas patogênicas de Enterobacteriacea (Rasmussen et al. 2006). Em estudos da acidose ruminal subaguda induzida pela alimentação com grãos ou com peletes de alfafa, verificou-se que ambas as dietas promoveram redução do $\mathrm{pH}$ e aumento da osmolaridade e concentração de LPS. Entretanto somente a dieta com grãos resultou em uma resposta inflamatória no epitélio ruminal (Khafipour et al. 2009a,b). Verificou-se que o microbioma do rúmen foi significativamente diferente na composição genética microbiana do rúmen com essas duas dietas que promoveram a acidose ruminal (Khafipour et al., 2009c). Demonstrou-se também que, em condições de menor $\mathrm{pH}$ ruminal ocorre elevação de uma população de E. coli acido resistente que contem genes de fatores de virulência que promoveriam processos inflamatórios em acidoses ruminais subagudas (Khafipour et al. 2011).

\section{CONCLUSÃO}

A população ruminal de bactérias Gram negativos aeróbias ou anaeróbias facultativas no fluido ruminal é semelhante para bovinos de corte zebuínos de diferentes categorias, criados em pastagem tropical lignificada. Entretanto esses microrganismos apresentam população significativamente maior para novilhos alimentados sem volumoso e com acidose ruminal e Escherichia coli corresponde a Enterobacteriaceae mais frequentemente identificada no fluido ruminal desses animais, indicando desequilíbrio nesse ecossistema.

Agradecimentos.- Programas de Bolsa de Extensão (PBEXT), ao Banco do Nordeste, a Coordenação de Aperfeiçoamento de Pessoal de Nível Superior (CAPES), Fundação de Amparo à Pesquisa do Estado de Minas Gerais (FAPEMIG) e Conselho Nacional de Desenvolvimento Científico e Tecnológico (CNPq).

\section{REFERÊNCIAS}

Anderson R.C., Harvey R.B., Byrd J.A., Callaway T.R., Genovese K.J., Edrington TS., Jung Y.S., McReynolds J.L. \& Nisbet D.J. 2005. Novel preharvest strategies involving the use of experimental chlorate preparations and nitro-based compounds to prevent colonization of food producing animals by foodborne pathogen. Poult. Sci. 84(4):649-654.

AOAC 2005. Official methods of analysis of the Association Analytical Chemists. 18th ed. Gaithersburg, Maryland.

Aung A., Ngwe T., Meulen U., Ngwe T., Gessler F. \& Bohnel H. 2006. Control of Leucaena toxicosis in Myanmar using IBT-Goettinger Bioreactor grow mimosine degrading ruminal Klebsiella spp. Tropentag 2006 - Conference on International Agricultural Research for Development,
University of Bonn, Alemanha. Disponível em <http://www.tropentag. de/2006/abstracts/full/202.pdf> Acesso em 10 mai. 2013.

Callaway T.R., Anderson R.C. \& Genovese K.J. 2002. Sodium chlorate supplementation reduces E. coli 0157:H7 populations in cattle. J. Anim. Sci. 80(6):1683-1689.

Diez-Gonzalez F., Callaway T.R., Menas G.K. \& Russel J.B. 1998. Grain Feeding and the Dissemination of Acid-Resistant Escherichia coli from Cattle. Science 281(5383):1666-1668.

Dirksen G. 1993. Rosenberger Exame Clínico dos Bovinos. $3^{3}$ ed. Guanabara Koogan, Rio de Janeiro. 419p.

Duse A., Waller K.P., Emanuelson U., Unnerstad H.E., Persson Y. \& Bengtsson B. 2015. Risk factors for antimicrobial resistance in fecal Escherichia coli from preweaned dairy calves. J. Dairy Sci. 98(1):500-516.

Freitas C.E.S., Almeida P.N.M., Duarte E.R., Abrão F.O., Careli R.T. \& Geraseev L.C. 2014. Aerobe and anaerobe facultative Gram-negative bacteria rodshaped in the ruminal fluid of dairy cattle fed with different diets containing tropical forages. Arch. Med. Vet. 6:457-462.

Jacobson L.H., Nagle T.A., Gregory N.G., Bell G., Roux G.L. \& Haines J.M. 2002. Effect of feeding pasture-finished cattle different conserved forages on Escherichia coli in the rumen and faeces. Meat Sci. 82(1):93106.

Khafipour E., Krause D.O. \& Plaizier J.C. 2009a. A grain based subacute ruminal acidosis challenge causes translocation of lipopolysaccharide and triggers inflammation. J. Dairy Sci. 92(1):1060-1070.

Khafipour E., Krause D.O. \& Plaizier J. 2009b. Alfalfa pellet induced subacute ruminal acidosis in dairy cows increases bacterial endotoxin in the rumen without causing inflammation. J. Dairy Sci. 92(1):17121724.

Khafipour E., Li S., Krause D.O. \& Plaizier J. 2009c. Rumen microbiome composition using two nutritional models of subacute ruminal acidosis (SARA). Appl. Environ. Microbiol. 75(1):7115-7124

Khafipour E., Plaizier J.C., Aikman P.C. \& Krause D.O. 2011. Population structure of rumen Escherichia coli associated with subacute ruminal acidosis (Sara) in dairy cattle. J. Dairy Sci. 94(1):351-360.

Krause D.O., Smith W.J.M., Conlan L.L., Gough J.M., Williamson M.A. \& McSweeney C.S. 2003. Diet influences the ecology of lactic acid bacteria and Escherichia coli along the digestive tract of cattle: neural networks and 16S Rdna. Microbiology 149(1):57-65.

Krogh N. 1999. Studies on alterations in the rumen fluid of sheep, especially concerning the microbial composition, when readily available carbo-hydrates are added to the food. I. Acta Vet. Scand. 1(1):74-97.

Lin C.W., Tran D.T., Lai C.Y., Pole Y. \& Wu C.H. 2010. Response surface optimization for ethanol production from Pennisetum Alopecoider by Klebsiella oxytoca THLC0409. Biomass Bioenviron. 1(12):1-8.

McFaddin J.F. 2000. Biochemical Tests for Identification of Medical Bacteria. 3rd ed. Lippincott Williams and Wilkins, Philadelphia. 912p.

Miranda Neto E.G., Afonso J.A.B., Mendonca C.L. \& Almeida M.Z.P.R.B. 2005. Estudo clínico e características do suco ruminal de caprinos com acidose láctica induzida experimentalmente. Pesq. Vet. Bras. 25(2):7378.

Murray P.R., Rosenthal K.S. \& Pfaller M.A. 2006. Microbiologia médica. 6a ed. Elsevier, Rio de Janeiro. 979p.

Murray P.R., Baron E.J., Jorgensen J.H., Landry M.L. \& Pfaller M.A. 2007. Manual of Clínical Microbiology. 9th ed. American Society for Microbiology, Washington, DC. 2488p.

Ostling C. \& Lindgren S. 2006. Influences of enterobacteria on the fermentation and aerobic stability of grass silages. Grass Forage Sci. 50(1):4147.

Pessoa G.V.A. \& Silva E.A.M. 1972. Meios de Rugai e lisina-motilidade combinados em um só tubo para a identificação presuntiva de enterobactérias. Revta Inst. Adolfo Lutz 32(1):97-100.

Rasmussen M.A., Cray Jr W.C., Casey T.A., Casey T.A. \& Whipp S.C. 2006. Rumen contents as a reservoir of enterohemorrhagic Escherichia coli. FEMS Microb. Lett. 114(1):79-84.

Ruiz-Lacaz R. 1992. Microbiologia Zootécnica. Roca, São Paulo, p.123-167. 
Russell J.B., Diez-Gonzalez F. \& Jarvis G.N. 2000. Invited review: effects of diet shifts on Escherichia coli in cattle. J. Dairy Sci. 83(4):863-873.

Scot D.E., Callaway T.R., Wolcott R.D., Sun Y., McKeehan T., Hagevoort R.G. \& Edrington T.S. 2008. Evaluation of the bacterial diversity in the feces of cattle using 16S rDNA bacterial tag-encoded FLX amplicon pyrosequencing. BMC Microb. 8(1):125-137.

Singh B., Bhat T.K., Sharma O.P., Kanwar S.S., Rahi P. \& Gulati A. 2012. Isola- tion of tannase-producing Enterobacter ludwigii GRT-1 from the rumen of migratory goats. Small Rumin. Res. 102(1/2):172-176.

Stevens M.P., Diemen P.M.V., Dziva F. Jones P.W. \& Wallis T.S. 2002. Options for the control of enterohaemorrhagic Escherichia coli in ruminants. Microbiology 148(12):3767-3778.

Willians A.G. \& Coleman G.S. 1991. The Rumen Protozoa. Springer-Verlag, New York. 423p. 